\title{
Unexpected mitochondrial lineage diversity within the genus Alonella Sars, 1862 (Crustacea: Cladocera) across the Northern Hemisphere
}

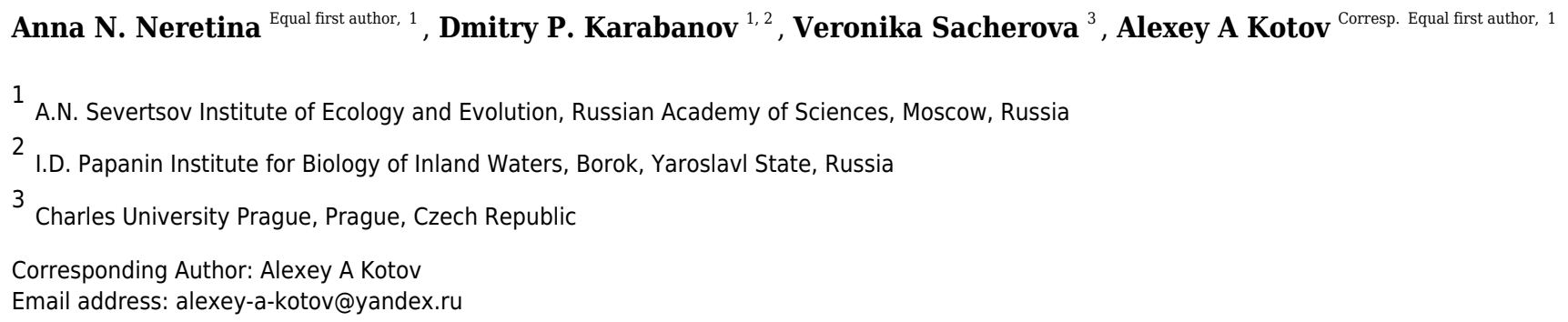

Representatives of the genus Alonella Sars (Crustacea: Cladocera: Chydorinae) belong to the smallest known water fleas. Although species of Alonella are widely distributed and often dominate acidic and mountain water bodies, their diversity is poorly studied. Morphological and genetic approaches have been complicated by the minute size of these microcrustaceans. As a result, taxonomists have avoided revising these species. Here, we present genetic data on Alonella species diversity across the Northern Hemisphere with particular attention to the $A$. excisa species complex. We analyzed $8216 \mathrm{~S}$ rRNA sequences (all newly obtained), and $78 \mathrm{COI}$ sequences (39 were newly obtained). The results revealed at least twelve divergent phylogenetic lineages, possible cryptic species, of Alonella, with different distribution patterns. As expected, the potential species diversity of this genus is significantly higher than traditionally accepted. The $A$. excisa complex is represented by nine divergent clades in the Northern Hemisphere, some of them have relatively broad distribution ranges and others are more locally distributed. Our results provide a genetic background for subsequent morphological analyses, formal descriptions of Alonella species and detailed phylogeographical studies. 
1

3

4

5 Kotov $^{1 *}$

6

7

8

9

10

11

12

13

14

15

16

17

18

19

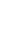

\section{Unexpected mitochondrial lineage diversity within the genus Alonella Sars}

(Crustacea: Cladocera) across the Northern Hemisphere

Anna N. Neretina ${ }^{1 *}$, Dmitry P. Karabanov ${ }^{1,2}$, Veronika Sacherová ${ }^{3}$ and Alexey A.

${ }^{1}$ Laboratory for Ecology of Aquatic Communities and Invasions, A.N. Severtsov Institute

of Ecology and Evolution, Russian Academy of Sciences, Moscow, Russia.

${ }^{2}$ Laboratory of Fish Ecology, I.D. Papanin Institute for Biology of Inland Waters, Russian

Academy of Sciences, Borok, Yaroslavl Area, Russia.

${ }^{3}$ Department of Ecology, Charles University, Prague, Czech Republic.

* Equal first authors

Corresponding author: Alexey A. Kotov ${ }^{1}$

\section{Abstract}


21 the smallest known water fleas. Although species of Alonella are widely distributed and often

22 dominate acidic and mountain water bodies, their diversity is poorly studied. Morphological and

23 genetic approaches have been complicated by the minute size of these microcrustaceans. As a

24 result, taxonomists have avoided revising these species. Here, we present genetic data on

25 Alonella species diversity across the Northern Hemisphere with particular attention to the $A$.

26 excisa species complex. We analyzed 82 16S rRNA sequences (all newly obtained), and 78 COI

27 sequences (39 were newly obtained). The results revealed at least twelve divergent phylogenetic

28 lineages, possible cryptic species, of Alonella, with different distribution patterns. As expected,

29 the potential species diversity of this genus is significantly higher than traditionally accepted.

30 The $A$. excisa complex is represented by nine divergent clades in the Northern Hemisphere, some

31 of them have relatively broad distribution ranges and others are more locally distributed. Our

32 results provide a genetic background for subsequent morphological analyses, formal descriptions

33 of Alonella species and detailed phylogeographical studies.

Subjects: Freshwater Biology, Biodiversity, Invertebrates 


\section{Introduction}

40

41

Water fleas (Crustacea: Cladocera) are microscopic crustaceans common to continental

42 waters (Kotov, 2013). Daphnia O.F. Müller is familiar to the public as a study subject in

43 classrooms and as a food source in the aquarium industry. But related cladocerans that are crucial

44 elements in littoral and benthic ecosystems are mostly unknown to the public. A rough estimate

45 of the approximate number of cladoceran individuals in the World, based on the total area of

46 inland waters being $10^{6} \mathrm{~km}^{2}$ and an underestimated average number of cladocerans being 1000

47 individuals per $1 \mathrm{~m}^{2}$, gives $10^{15}$ individuals (Smirnov \& Kotov, 2010). Most of these cladocerans

48 do not belong to the genus Daphnia, but their ecological importance is immense and very little is

49 known about their diversity.

50 While Daphnia is universally accepted as an important model for ecological,

51 toxicological and genetic studies (Lampert, 2011), we still know very little about other water

52 fleas. However, in the last ten years, substantial progress has been made by integrative

53 taxonomic and phylogenetic studies of non-model species groups from the families Daphniidae

54 (Ishida, Kotov \& Taylor, 2006; Petrusek et al., 2008; Dlouhá et al., 2010; Kotov \& Taylor,

55 2010; Popova et al., 2016; Bekker et al., 2018; Karabanov et al., 2018; Kotov \& Taylor, 2019;

56 Kotov et al., 2020), Bosminidae (Kotov, Ishida, \& Taylor, 2009; Faustova et al., 2011; 2017),

57 Eurycercidae (Bekker, Kotov \& Taylor, 2012;), Moinidae (Petrusek, Černý \& Audenaert, 2004; 
58 Bekker et al., 2016; Montoliu-Elena, Elías-Gutiérrez \& Silva-Briano, 2019; Ni et al., 2019),

59 Chydoridae (Sacherová \& Hebert, 2003; Belyaeva \& Taylor, 2009; Kotov et al., 2016; Sinev,

60 Karabanov \& Kotov, 2020), Polyphemidae (Xu et al., 2009) and Leptodoridae (Xu et al., 2011).

61 Based on these works, water fleas are no longer considered as exemplars for cosmopolitanism

62 (sensu D.G. Frey $(1982,1987))$. There has also been significant progress in large-scale

63 biogeographic reconstructions for these tiny animals. But the slogan "everything is everywhere"

64 (Baas Becking, 1934) still may be applied to the biogeography of taxonomically difficult groups

65 of cladocerans, such as the genus Alonella Sars (Anomopoda: Chydoridae: Chydorinae). This

66 genus includes the smallest representatives of the water fleas known to date. The adult specimens

67 of Alonella do not exceed $0.45 \mathrm{~mm}$ in length and are barely visible to the naked eye (Smirnov,

68 1971, 1996). Although Alonella is widely distributed all around the World and often abundant in

69 acidic and mountain water bodies (Smirnov, 1996; Van Damme \& Eggermont, 2011), its

70 diversity is still poorly studied. Morphological and genetic study of Alonella is made difficult by

71 the small body size. Although some other small-bodied cladoceran taxa are intensively studied

72 now, taxonomists have avoided revision of the species of Alonella. Since N.N. Smirnov's

73 monographs on the chydorids (Smirnov, 1971, 1996), only a single new species of Alonella has

74 been described (Alonso \& Kotov, 2017). Also, few attempts to isolate and sequence DNA have

75 been carried out for this genus mainly due to the molecular barcoding efforts (Costa et al., 1997; 
76 Jeffery, Elías-Gutiérrez \& Adamowicz, 2011; Prosser, Martinez-Arce \& Elias-Gutierrez, 2013)

77 and studies of the chydorid generic relationships (Sacherová \& Hebert, 2003).

78 In fact, only three morphospecies of Alonella: A. nana (Baird), A. exigua (Lilljeborg) and

79 A. excisa (Fischer) (Fig. 1A-F) are recognizable now in the Northern Hemisphere following the

80 Smirnov's key (Smirnov, 1996). A. nana is characterized by a sub-globular body shape and

81 prominent diagonal lines on the valves (Smirnov, 1971; Hudec, 2010) (Fig. 1A-B). A. excisa and

82 A. exigua have an elongated body and polygonal ornamentation (Fig. 1C-F). There are small

83 dots within each polygon in A. exigua (Fig. 1C-D), while each polygon in A. excisa carries short

84 parallel striation (Fig. 1E-F). Each of these three morphospecies has a very wide geographic

85 range. As such, they are candidates for groups of sibling species (Frey, 1982, 1987). Indeed,

86 preliminary morphological evidence suggested the existence of several species within the $A$.

87 excisa complex (Kotov et al., 2013). The status of other Alonella and Alonella-like taxa (out of

88 nana, excisa and exigua groups) (Smirnov, 1971, 1996) remains unclear. The aim of the present

89 work is to elucidate the mitochondrial lineage diversity and preliminary biogeography of

90 Alonella (especially of the A. excisa species complex) across the Northern Hemisphere using

91 different methods of the OUT delimitation. The evidence is based on variation in mitochondrial

92 16S ribosomal RNA (16S) and cytochrome c oxidase subunit I (COI) genes.

93 
95

96

97

98

99

100

101

102

103

104

105

106

107

108

109

110

111

112

\section{Ethics statement}

Field collection in public property in Russia does not require permissions. Sampling in the state natural reserves of Russia was conducted with special verbal permission of their heads (O.P. Elizarova, Pinezhsky State Natural Reserve; T.I. Shpilenok, Kronotsky Biosphere Reserve;

Y.P. Sushitsky, Khanka Nature Reserve). Sampling in Ethiopian was performed in the frame of the Joint Ethio-Russian Biological Expedition, curated by the Ministry of Environment, Forest and Climate Change of Ethiopia, and does not require special permission. Sampling in Mongolia was performed in the frame of the Joint Russian-Mongolian Complex Biological Expedition, curated by the Ministry of Nature, Environment and Tourism of Mongolia, and does not require especial permission. Samples in South Korea were collected in the frame of cooperation between A.A. Kotov and the National Institute of Biological Resources of Korea and does not require special permission. Some samples from Canada, the Czech Republic, Mexico and U.S.A. were provided by our colleagues having permissions to collect them due to their scientific activity in the governmental institutes in the corresponding countries. Field works did not affect endangered or protected species. 
114 construction and fixed immediately after sampling in $96 \%$ ethanol. All samples were

115 preliminarily inspected in the laboratory under a binocular stereoscopic microscope LOMO

116 (Open Joint-Stock Company, Russia). In samples where Alonella taxa were detected, the whole

117 volume of sample was examined under light microscope Olympus BX41 for accurate

118 identification based on morphological characters via standard keys (Smirnov, 1971, 1996).

119 Selected individuals were studied under a scanning electron microscope CamScan MV 2300

120 (Tescan, Czech Republic) as described previously (Kotov, 2013; Neretina \& Kotov, 2015).

\section{DNA sequencing}

123 One to three parthenogenetic females from each population (see Supplementary S1 Table

124 on-line) predominantly of the $A$. excisa species complex were studied for genetic profiles.

125 Identification of each parthenogenetic female used in the genetic analysis was especially re-

126 checked under a stereoscopic microscope in order to avoid possible mistakes related with

127 situations when a sample contained several Alonella species simultaneously. Selected individuals

128 were placed into 96-well PCR plates and air-dried. DNA from individual crustaceans was

129 extracted in $50 \mu \mathrm{l}$ of proteinase K solution, according to the protocol of Schwenk et al. (1998).

130 PCR reactions were carried out in $25 \mu \mathrm{L}$ volume, containing $5 \mu \mathrm{L}$ of genomic DNA, $6.2 \mu \mathrm{L}$ of

131 distilled $\mathrm{H}_{2} \mathrm{O}, 0.65 \mu \mathrm{L}(10 \mu \mathrm{M})$ of each primer to amplify either COI (COI-F: 5'- 
132 TGTAAAACGACGGCCAGTTCTASWAATCATAARGATATTGG-3'; COI -R: 5'-

133 CAGGAAACAGCTATGACTTCAGGRTGRCCRAARAATCA-3') or 16S (16S-F: 5'-

134 CCGGAATTCCGCCTGTTTATCAAAAACA-3'; 16S-R: 5'-

135 CCCAAGCTTCTCCGGTtTGAaCtCAGAT-3') (see details on COI primers in Prosser,

136 Martinez-Arce \& Elias-Gutierrez (2013) and details on 16S primers in Simon et al. (1994)) and

$13712.5 \mu \mathrm{L}$ of PPP Master Mix (Top-Bio, the Czech Republic) in a thermocycler GeneTouch

138 (Hangzhou Bioer Technology Co., China). The PCR cycles both for COI and 16S fragments

139 included the following steps: initial denaturation at $92{ }^{\circ} \mathrm{C}$ for $3 \mathrm{~min}, 40$ cycles (denaturation at 94

$140{ }^{\circ} \mathrm{C}$ for $1 \mathrm{~min}$, annealing at $50{ }^{\circ} \mathrm{C}$ for $1 \mathrm{~min}$, and elongation at $72{ }^{\circ} \mathrm{C}$ for $1.5 \mathrm{~min}$ ), and final

141 elongation at $72{ }^{\circ} \mathrm{C}$ for $5 \mathrm{~min}$. Amplified PCR products were sequenced using forward and

142 reversed primers or only via forward primers. In the first case, a single consensus sequence was

143 assembled using the forward and reverse sequences using CodonCode Aligner v. 6.0.2

144 (CodonCode Corp, USA) and checked for possible stop-codon presence. DNA sequences were

145 submitted to the NCBI GenBank database (accession numbers MN608113-MN608151 for COI

146 and MN598677-MN598759 for 16S) (Supplementary S1 Table on-line).

147

\section{Analysis of sequences and reconstruction of phylogeny}

The authenticity of all newly obtained sequences was verified by BLAST comparisons

150 (Boratyn et al., 2013). We also added two species of Chydoridae (Alona affinis (Leydig, 1860) 
151 and A. setulosa Megard, 1967) as outgroups and existing sequences of Alonella from GenBank

152 (Supplementary S1 Table on-line) to our study. The sequences were aligned via a software

153 package MAFFT v.7 (Katoh \& Standley, 2016) on the server of the Computational Biology

154 Research Center, Japan (http://mafft.cbrc.jp). For alignment of the protein coding COI locus we

155 used the "Translation Align" option with strategy FFT-NS-i. For the 16S locus, we used the Q-

156 INS-i algorithm, which considers secondary structure. Searching of appropriate models and

157 partitioning schemes were fulfilled via ModelFinder v.1.6.9 (Kalyaanamoorthy et al., 2017) on

158 the web-service of the Center for Integrative Bioinformatics Vienna, Austria

159 (http://www.iqtree.org). Selection of the best model was carried out based on the best minimal

160 values of the Bayesian information criterion (BIC) (Posada \& Buckley, 2004). Parameters of

161 nucleotide substitutions were identified in ModelFinder (Kalyaanamoorthy et al., 2017) as

$162 \mathrm{~K} 3 \mathrm{Pu}+\mathrm{F}+\mathrm{G} 4$ for $16 \mathrm{~S}$, and for COI triplets: $1^{\text {st }}-\mathrm{TN}+\mathrm{F}+\mathrm{I}, 2^{\text {nd }}-\mathrm{TVM}+\mathrm{F}+\mathrm{I}$ and $3^{\text {rd }}-\mathrm{HKY}+\mathrm{F}+\mathrm{G} 4$.

163 Parameters of the model BIC were almost identical to those found via the corrected Akaike's

164 information criterion (AICc) (Posada \& Crandall, 2001).

165 Phylogeny reconstruction was carried out for each locus separately. Also, we

166 reconstructed a joint consensus tree based on the whole set of unlinked data using the maximum

167 likelihood (ML) or Bayesian (BI) methods. For ML analysis we used an algorithm IQ-TREE

168 v.1.6.9 (Nguyen et al., 2015), as implemented on the CIBIV web-server (Trifinopoulos et al.,

169 2016). Each set of sequences was analyzed based on the best model, which was automatically 
170 calculated by W-IQ-TREE (Trifinopoulos et al., 2016). As the branch supporting test, we used

$1711 \mathrm{k}$ replics in UFbootstrap2, requiring significantly smaller computational resources as compared

172 with traditional supporting tests and demonstrating a higher effectiveness of such calculations

173 (Hoang et al., 2018). When conducting BI, the posterior probabilities (Bolstad, 2007) were

174 calculated in BEAST2 v.2.6 (Bouckaert et al., 2018). All parameters of substitution models were

175 identified for BI-trees via BEAUti (Drummond et al., 2012) (part of BEAST2 package) using the

176 BIC criterion. In each BEAST2-analysis, we conducted four independent runs of MCMC (100M

177 generations, with selection of each 10k generation) with effectiveness control in " $\mathrm{R}$ We There

178 Yet" (RWTY) for "R" statistical language (Warren, Geneva \& Lanfear, 2017). A consensus tree

179 based on the maximum clade credibility (MCC) was obtained in TreeAnnotator v.2.6

180 (Drummond et al., 2012) with half increased burn-in rate determined in RWTY (but no less than

$18120 \%)$.

182

ML-testing MEGA-X (Kumar et al., 2018) rejected a strict molecular clock. Therefore,

183 we used an uncorrected relaxed clock with lognormal distribution, allowing to vary the

184 substitution speed in different portions of the tree (Drummond et al., 2006). Speciation was

185 analyzed using the Yule process approximation (Steel \& McKenzie, 2001). Alona sequences from

186 the GenBank are used as a priori designated outgroup. Having no additional information on

187 stationary frequencies and parameters in nucleotides substitution, we ignored the priors of

188 Dirichlet's distribution due to their weak positive influence on the phylogeny reconstructions 
189 (Sarver et al., 2019). After conclusion on the full consensus in the main clades between BI and

190 ML, we represented in our illustrations only ultra-metric BI trees, with branches supports for key

191 nodes only.

192 Correlation between phylogenies based on different genetic loci is a special issue in every

193 phylogenetic reconstruction (Nei \& Kumar, 2000). We carried out a comparison between trees

194 made in BEAST2 separately for $16 \mathrm{~S}$ and COI, analyzing sequences exactly from the same

195 vouchers on the tanglegram constructed in Dendroscope-3 (Scornavacca, Zickmann \& Huson,

196 2011). General topologies of reconstructed 16S and COI trees were similar, which allowed us to

197 analyze not only individual gene phylogenies, but also to use a more powerful coalescent

198 methods to analyze the relationship between the reconstructed trees through the calculation of a

199 multigenic supermatrix (BEAST2 (Bouckaert et al., 2019)) and by merging individual gene trees

200 (ASTRAL-III (Zhang et al., 2018)). No fundamental differences of both tree topologies were

201 found. We deleted branches with low support (Zhang et al., 2018). However, this transformation

202 failed to improve the output tree. Thus, we have a justification for our reconstruction of

203 multilocus phylogeny and combination of data even in the presence of "gaps" (Molloy \&

204 Warnow, 2018) as we did not have sequences of both genes from all specimens.

205

206

Species delimitation

Peer) reviewing PDF | (2020:09:52695:2:0:CHECK 18 Dec 2020) 

sequence-based trees (Kartavtsev, 2018), and we used three most common approaches to the

209 OTUs delimitation based on single locus data, as well as the whole dataset. Since a preliminary

210 prior data sorting on the possible OTUs is required for most computer packages, we conducted

211 an analysis of the tree reconstruction for each locus separately based on the ABGD distance

212 method, coalescence models in the 'splits' and 'bGMYC' packets, as well as through the Poisson 213 analysis of mPTP.

214 The simplest method based on analysis of a threshold of divergence, Automatic Barcode

215 Gap Discovery (ABGD) (Puillandre et al., 2012), was realized based on the web-server Atelier

216 de BioInformatique, France (http://wwwabi.snv.jussieu.fr/public/abgd/abgdweb.html). Single

217 values for both mitochondrial loci were selected by us: Pmin $=0.001, \operatorname{Pmax}=0.1$, Steps $=100$,

$218 \mathrm{X}=10, \mathrm{Nb}=25$.

219 The second method, applying the coalescence approach based on general mixed Yule-

220 coalescent model (GMYC) (Pons et al., 2006) with the "classic" implementation of GMYC, was

221 performed in the 'splits' package (Fujisawa \& Barraclough, 2013) for Microsoft "R-Open \&

222 MKL" software v.3.5.3 x64 (http://mran.microsoft.com/). As the input tree, we used an

223 ultrametric BI-tree made in BEAST2 for each locus. As it is known that realization of GMYC in

224 the case of a complicated structure of natural populations leads to considerable over-estimation

225 of the number of recognizable taxonomic units (Lohse, 2006), we used Bayesian realization of 
226 the general mixed Yale model and coalescence in order to increase (at least partly) the reliability

227 of GMYC conclusions (Reid \& Carstens, 2012) in the package 'bGMYC' for "R". Input trees for

228 'bGMYC' were the same as for the 'splits' analysis. Sorting, re-rooting of the trees and

229 removing the outgroups was carried out via the " $\mathrm{R}$ " package according to the script of Sweet et

230 al. (2018). We randomly selected 100 ultrametric trees from the primary set to the 'bGMYC'

231 processing with the following parameters: 100k MCMC generations with 50\% annealing; the

232 range of threshold values from 2 to the maximum number of sequences in the data set; start

233 values for both Yale and coalescence models according to Reid \& Carstens (2012) as the most

234 usable for the majority datasets. These sets allowed us to obtain the distribution of "Coalescence

235 to Yule">> , what is a sign of a good fit of the model parameters to the data. The threshold level

236 of the cladogenesis reliability was accepted as $\mathrm{P}>0.95$ and $\mathrm{P}>0.99$, which allows us to reduce the

237 probability of an excessive lumping in the taxonomic structure.

Poisson tree processes (PTP). This approach aims to distinguish speciation processes among the

240 species from diversification processes within the species, but it analyzes the number of

241 substitutions between branching events instead of time intervals. For data processing, we used

242 multi-rate Poisson Tree Processes, mPTP (Kapli et al., 2017) on the web-server of Heidelberg

243 Institute for Theoretical Studies (http://mptp.h-its.org/). As the input tree, we used the

244 phylogenetic ML-tree obtained used W-IQ-TREE for each locus. 
246 (http://www.python.org) was used as a method for multi-locus taxonomy. This method is based

247 on the identification of a transition point between species branching and branching within

248 species via estimation of observed and expected levels of genes congruence according to the

249 coalescence theory for rooted triplets topologies. We used an option of testing of the OTUs

250 apriori partitioning on the consensus ultrametric tree in BEAST2 for both loci unlinked.

251 However, this mechanistic approach does not allow to adjust the model taking into account the

252 genetic features and biology of different groups of organisms. As an alternative method, we used

253 a Bayesian approach for the delimitation of multi-species coalescence model using molecular

254 sequences from multiple loci in STACEY v.1.2.4 (Jones, 2017) for BEAST2. In fact, this

255 method is a version of the multi-species coalescence model used in *BEAST (Heled \&

256 Drummond, 2010). There the birth-death-collapse model is used in order to estimate the species

257 tree (Jones, 2017). Final phylogenetic relationships were estimated via STACEY in four

258 independent runs for the whole data set. Each run consisted of 50M MCMC generations, with

259 selection of every $10 \mathrm{k}$ with $10 \%$ pre-annealing. STACEY $\log$ files were examined in Tracer

260 v.1.7.1 (Rambaut et al., 2018) to assess whether the runs have reached the stationary phase and

261 converge on model parameters (ESS $>400)$. Support of topologies was evaluated in STACEY by

262 constructing a tree of maximum reliability in TreeAnnotator (part of BEAST2 package) after

263 rejection of a half of all estimated trees. Species delineation (based on the trees evaluated in 
264 STACEY) was carried out using a Java-application 'speciesDA'

265 (http://www.indriid.com/software.html).

266 An input consensus multigene ultrametric tree was the same for "tr2" and STACEY. For

267 this, we combined both sequences in the unified supermatrix via SequenceMatrix v.1.8 (Vaidya

268 et al., 2011), a nucleotide substitution model for each locus was defined in ModelFinder (for the

269 entire 16S sequences and individually for each nucleotide position in the triplet for COI). We

270 deliberately did not delete any sequences with incomplete and missing data, because this

271 approach can greatly reduce the accuracy of the tree reconstruction (Molloy \& Warnow, 2018).

272 Further analysis was made in the same way as for phylogeny reconstruction, in BEAST2, but

273 with $100 \mathrm{M}$ of MCMC generations and sampling every $100 \mathrm{k}$ tree. Due to a high uncertainty of

274 the reconstructed tree, we used a final 50\% annealing; in our subsequent analysis we used 500

275 trees from each run. However, the concatenation-based approach (Rokas et al., 2003) is

276 reasonably criticized due to existence of a convergence between restored gene trees and the

277 common species tree (Maddison \& Wiens, 1997). To derive a species tree from these different

278 gene trees, we used the multiple fusion technique implemented in ASTRAL-III v.5.6.3 (Zhang et

279 al., 2018). No significant differences between the results of two analyses were found in

280 Dendroscope-(Huson \& Scornavacca, 2012), so we used the BI tree for further conclusions.

281 In order to reduce the impact of a population structure to phylogenetic reconstructions,

282 we previously divided the entire dataset into morphologically defined groups (excisa-like, 
283 exigua-like and nana-like) (Tables 1, 2). Calculations of the nucleotide diversity indices (Nei \&

284 Kumar, 2000), demographic indicators (mismatch distribution and coalescence modeling for

285 population growth and divergence) and the neutrality tests were performed in dnaSP v. 6.12

286 (Rozas et al., 2017). In order to check the neutrality of the loci and roughly describe possible

287 demographic processes, we carried out the Fs test of neutrality $(F u, 1997)$ and $\mathrm{R} 2$ statistics

288 (Ramos-Onsins \& Rozas, 2002) as the best ways of such analysis (Ramirez-Soriano et al., 2008;

289 Garrigan, Lewontin, \& Wakeley, 2010). The platform MEGA-X (Kumar et al., 2018) was used

290 to calculate genetic distances. We selected "simple" $p$-distances as more preferable for DNA

291 barcoding (Collins et al., 2012), as there is no significant difference between uncorrected and

292 corrected substitution models in case of a sufficiently large dataset (Nei \& Kumar, 2000).

293

294

295

296

297

298

299

300

\section{Results}

The 16S fragment was successfully amplified and sequenced from most studied

individuals. A high rate of unsuccessfully PCRs for COI fragment (27\%) is resulted presumably

from the presence of sequence mutations at the primer binding sites, as even "universal primers"

(Prosser, Martinez-Arce \& Elias-Gutierrez, 2013; Elías-Gutiérrez et al., 2018) did not work

properly. The alignment contained 82 newly obtained $16 \mathrm{~S}$ rRNA sequences (400 bp), 39 original

Peer] reviewing PDF | (2020:09:52695:2:0:CHECK 18 Dec 2020) 
301 (626 bp) and 39 previously obtained COI sequences deposited in NCBI Genbank or BOLD

302 (Supplementary S1 Table on-line).

303

Both loci were characterized by a relatively high haplotype and nucleotide diversity and a

304 relatively low $\mathrm{G}+\mathrm{C}$ portion in the coding COI locus, that, along with previous data (Kotov et al.,

305 2016), may be characteristic of the chydorids in toto. Results of the neutrality tests for different

306 loci for different groups of populations may indicate multidirectional demographic processes in

307 different lineages and in different loci. Thus, the values of Fs $>>0$ at R2 $>0$ were characteristic for

308 both loci of the excisa-like taxa and may indicate a significant genetic differentiation within this

309 group (with the possibility of splitting/mixing processes in the populations). The exigua-like

310 group looks more homogeneous, and the high values of Fs and R2 for COI can be explained by

311 an effect of the small sample size. However, these results demonstrated the need to study in

312 detail the genetic structure of large groups of Alonella populations and to resolve the taxonomic

313 uncertainty in these lines.

314

Our original sequences together with the GenBank sequences could be assigned to 12

315 phylogenetically divergent clades, well supported statistically. We numbered all major clades by

316 capital letters from "A" to " $\mathrm{L}$ ", the clades A-K are primarily defined based on the variation in

317 the $16 \mathrm{~S}$ tree (Fig. 2). The clade L is present in the COI tree only (Fig. 3) due to lack of $16 \mathrm{~S}$

318 sequences from Mexican populations. In the COI tree, only 8 major clades were represented: B,

319 C, D, E, G, H, J, L (Fig. 3), as we failed to obtain the sequences for clades A, F, I and K. In total, 
320 we differentiated a single major clade (A) for A. nana, two major clades (B-C) of the A. exigua

321 complex and nine major clades (D-L) of the A. excisa complex (Figs. 2, 3).

322 Alonella nana (Fig. 4, upper panel, Supplementary S1 Table on-line). Clade A was

323 represented by two regional subclades: A1 was found in Europe and A2 was found in a single

324 locality in North America (Fig. 4A).

325 A. exigua complex (Fig. 4, upper panel). Clade B was widely distributed through the

326 northern Palaearctic; sequences from Siberia, Mongolia and European Russia form a subclade

327 B1, while a single Central European sequence formed a separate subclade B2 (The subclade B1 was paraphyletic in the $16 \mathrm{~S}$ tree) (Fig. 2). The clade $\mathrm{C}$ was found in several localities of northern

329 North America forming a single subclade C1 (Newfoundland, Manitoba Ontario) (Fig. 4A).

Siberia, Eastern Siberia and Kamchatka) (the subclade D3 was paraphyletic in the $16 \mathrm{~S}$ tree). 
339 (Western Siberia). Clade H (Fig. 4, bottom panel) was exclusively European, and was

340 represented by subclade H1 (Central Europe and European Russia) (this subclade was

341 paraphyletic in the $16 \mathrm{~S}$ tree) and $\mathrm{H} 2$ (Central Europe only). Clade I was widely distributed in the

342 eastern portion of Eastern Siberia, Russian Far East and Manitoba - it formed the subclades I1

343 (Eastern Siberia and Russian Far East) and I2 (Eastern Siberia and Manitoba) (the latter was

344 paraphyletic in the $16 \mathrm{~S}$ tree). Clade J was found only in the Ethiopian Bale Mountains, it

345 contained two subclades (J1 and J2) both from this local area. Clade K (with single subclade K1)

346 was found in a single locality in Ontario. Clade L (with single subclade L1) was found in the

347 Yucatan Peninsula (tropical Mexico) (Fig. 4, bottom panel).

348 Genetic differentiation between the major clades was great (p-distance was 12.1-25.1\%

349 for COI, and 10.6-27.2 for 16S, Supplemental S2 Table on-line) as compared to other

350 invertebrates. Such a level of genetic differentiation corresponded to (at least) the species level,

351 even if we applied the highest threshold values of such differences for the invertebrates (Hebert,

352 Ratnasingham \& deWaard, 2003; Hebert et al., 2004).

353 The tanglegrams for mitochondrial genes (Supplementary Fig. S1 on-line), and species

354 (Supplementary Fig. S2 on-line) had similar topologies, including the terminal branches. There

355 was strong agreement for the existence of the same major clades in both mitochondrial loci

356 (Supplementary Fig. S3 on-line). A few discrepancies in tree topologies were detected; however,

357 it was clear that a reliable reconstruction of the tree branching at the high hierarchical level 
358 would benefit from a full representation of all clades. Such sampling could not be provided for

359 objective reasons, i.e. part of the data was sourced from previously published studies.

360 Delimitation on the entire general multi-locus tree via different methods, including those based

361 on multi-species coalescence, was illustrated in Supplementary Figure S3 on-line. Major clades

362 were recognized as separate units by all algorithms.

363

364

\section{Discussion}

365

366

\section{Genetic basis for biodiversity understanding}

367

Based on a logics of the "standard screening threshold of sequence difference (10×

368

average intraspecific difference") (Hebert et al., 2004), we would have to conclude that each the

369

excisa, exigua and nana is represented by a single polymorphic species. However, the levels of

370

divergence in these complexes are significantly higher than it was previously found in most

371 animals (Ratnasingham \& Heber, 2003; Meier et al., 2006; Huemer et al., 2014; Čandek \&

372 Kuntner, 2015). Therefore, an alternative and much more realistic explanation is a high cryptic

373 variability within each studied complex. Possible morphological differences within the

374 aforementioned species complexes must be studied in detail.

375 Different delimitation approaches result in different number of distinct units, which may

376 possibly represent species (Fig. 5). The ABGD approach is known by its excessive splitting of 
377 the groups with high levels of polymorphism, and as a result, even "good" morphospecies could

378 be easily split into several groups, as it was already shown for Daphnia magna (Bekker et al.,

379 2018). Theoretically, these problems may have been resolved by using coalescent methods.

380 However, there are obvious "excesses" of such packets as 'splits' and 'tr2', working on the

381 simplest algorithm without an opportunity to correct model parameters based on knowledge

382 about the animal biology. As expected (Sukumaran \& Knowles, 2017), GMYC models in case of

383 Alonella tend to recognize some structured populations as real distinct species (Fig. 5). There are

384 also well-known methodological problems concerning the GMYC (Maddison \& Wiens, 1997;

385 Powell, 2012; Reid \& Carstens, 2012) and PTP (Zhang et al., 2013; Kapli et al., 2017)

386 applications. Usually mPTP delimitation is more conservative, only the large groups of

387 populations (Fig. 5) are recognized as species which allows to prevent an excessive splitting

388 (Tang et al., 2014; Vitecek et al., 2017). But based on both the analysis of individual trees and

389 species coalescence via several genes, we can state the presence of a complex species structure

390 within the Alonella genus. Moreover, the main phylogenetic lineages are supported in all

391 analyses.

392

As it was shown above, the lack of data on a mitochondrial locus can be compensated via

393 data on another locus, it allows us to carry out a reconstruction of the phylogenetic relationships

394 based on the mitogenomes of Alonella, to identify main phylogenetic lines, potential OTUs,

395 although they don't have to be recognized as "biological species" (Blaxter et al., 2005).

Peer] reviewing PDF | (2020:09:52695:2:0:CHECK 18 Dec 2020) 

exclusively European;

(3) Southern Far Eastern (E);

North America (C, F, K);

(6) Mexican Neotropical with unknown real range (L);

(7) Possible endemic Ethiopian (J).

412 Alonella. But geographic patterns for the divergent and minor clades of Alonella are concordant

413 to those from other cladoceran macro-taxa. A trans-Beringian distribution was observed in some

414 clades of the Polyphemus pediculus group (Xu et al., 2009) and the Chydorus sphaericus group 
415 (Belyaeva \& Taylor, 2009; Kotov et al., 2016). Clade B is widely distributed in the Northern

416 Palaearctic (in our samples, from the Czech Republic to Yakutia Republic), while its sister clade

417 C seems to be restricted to the North America, although presence of both clades in the Far East is

418 also possible. The same situation is observed in the Moina macrocopa species group, where $M$.

419 macrocopa s.str. is widely distributed in the Northern Palaearctic, while M. americana is

420 restricted to the New World (Montoliu-Elena, Elías-Gutiérrez \& Silva-Briano, 2019). The clades

421 widely distributed through all the whole northern Palaearctic are also known for the Polyphemus

422 pediculus group (Xu et al., 2009), Daphnia curvirostris group (Kotov \& Taylor, 2019; Kotov et

423 al., 2020), D. pulex group (Crease et al., 2010; Ballinger et al., 2013) and D. longispina

424 complex (Yin et al., 2018; Zuykova et al., 2019). Exclusively Nearctic clades are found within

425 many taxa (Bekker, Kotov \& Taylor, 2012; Xu et al., 2011). Clade E is found in the southern Far

426 East. According to our data, it is distributed from South Korea to Primorski Territory of Russia,

427 but potentially, this taxon may have a wider distribution range as records of thermophilic

428 Oriental taxa in the southern portion of the Russian Far East are not rare (Kotov, 2016). But,

429 most probably, this clade belongs to an endemic Far Eastern faunistic complex (Kotov \& Taylor,

430 2019; Kotov, 2016).

431 An example of the Alonella endemism is presumable a specific major clade $\mathrm{J}$ from

432 Ethiopian high mountains. In Ethiopia, populations, belonging to the clade J, were detected from

433 the same water bodies where another local endemic, Daphnia izpodvala, was found (Kotov \& 
434 Taylor, 2010) and they are never found in the tropical lowlands. At the same time, reliable

435 records of Alonella populations from other African countries are very limited. Such records are

436 known from Chad (Rey \& Saint-Jean, 1968), Fouta Djalon and adjacent mountain areas

437 (Dumont, 1981), Cameroon rain forests (Chiambeng \& Dumont, 2005), Rwenzori mountains

438 (Van Damme \& Eggermont, 2011). All these populations have not been studied via genetic

439 methods yet.

440 Surprisingly, during our study we found some cases of trans-continental geographic

441 ranges in Alonella (but only within the Holarctic). Thus, the European subclade A1 is a sister

442 group to A2 from North America (USA, MA) (Fig. 4, upper panel; Supplementary Fig. S2 on-

443 line). Most likely explanation lies in some past dispersion scenario, with subsequent independent

444 genetic evolution of these newly established populations. Such cases were previously

445 demonstrated for other cladocerans (Taylor \& Hebert, 1993; Marková et al., 2007; Millette et

446 al., 2011).

447

Appearance of the lineages $\mathrm{C}$ and $\mathrm{F}$ in Canada could be explained as a result of a trans-

448 Beringian transition (Fig.4, upper panel). Such a transition possibly took place only around 20

449 thousand years ago, which corresponds well with existence of a massive land bridge between

450 Eurasia and North America, Beringia. The level of genetic differences between them and their

451 sister groups (lineages B and E, respectively) in Eurasia is comparable to that between A1-A2.

452 The presence in Canada of the haplotype from the I2 subclade, close to the Yakutia-Primorsky 
453 haplotypes, could be also a consequence of recent anthropogenic introduction from Pacific Asia.

454 Similar patterns are known for other freshwater microcrustaceans (Ishida \& Taylor, 2007).

455

The phylogeographic situation is complicated in Canada (Fig. 4, upper and bottom

456 panels; Supplementary Fig. S2 on-line), where several sympatric main clades and/or subclades

457 were found (D2, K1, F1, C1, I2). The K1 lineage is probably ancestral to the rest of the Alonella

458 s.lat. taxa, and its status must be specially checked. The D2 clade is probably a North American

459 phylogenetic lineage of the widespread circumpolar group D, such patterns are already found in

460 Polyphemus pediculus (Xu et al., 2009). Probably, the subclade C1 and F1 are derived,

461 respectively, from the Eurasian group of populations B and the Far Eastern group E. The

462 comparable genetic distances between these North American and their ancestral groups may be a

463 consequence of their appearance as a result of a trans-Beringian transition. Unfortunately, the

464 Beringian zone is not sampled here, but Beringia apparently has an important role in the Alonella

465 biogeographic patterns and needs to be specially studied in the future based on numerous

466 samples.

467

468

Cryptic diversity of Alonella across the Northern Hemisphere and short comments

469

on the inter-generic subdivision of Alonella

470 Our study confirms the opinion that the real diversity of the water fleas is several times

471 higher than it is accepted now (Adamowicz \& Purvis, 2005). This situation is usual for 
472 freshwater animals of different groups (Mills et al., 2017; Schwentner et al., 2020). We found

473 several possible cryptic species within A. excisa and A. exigua species complex. To date,

474 characters of the parthenogenetic females have a very limited value for the species

475 discrimination within the A. excisa and A. exigua. Apparently, incorporation of males to

476 morphological analysis may improve the situation, as it was already shown for some other

477 chydorids (Belyaeva \& Taylor, 2009; Kotov et al., 2016; Garibian et al., 2018), but,

478 unfortunately, males only sporadically occur in the natural populations of Alonella, and, despite

479 our significant efforts, we have no materials with males from some interesting localities, such as

480 Ethiopia.

481

Before 2010, it was universally accepted that Alonella was a monophyletic genus,

482

although the delineation between several chydorid genera (Alonella, Disparalona, Pleuroxus and

Picripleuroxus) has been intuitive rather than based on accurate diagnostics (Neretina et al.,

2018). Hudec (2010) subdivided the European taxa of the genus Alonella into two subgenera,

Alonella s.str. and Nanalonella. The latter taxon has included a sole species, $A$. (N.) nana, with a

globular shape of body, a single minute tooth on posteroventral portion of valve and a very short

subquadrangular postabdomen. According to Hudec (2010), Alonella s.str. has included in

Europe two species: $A$. excisa and $A$. exigua. Both morphospecies are characterized by a 
491 group to A. exigua complex (clade B and C) (Fig. 2), in conflict with the subgeneric proposal by

492 Hudec (2010). Variability in the number and shape of these denticles in some chydorids was

493 previously discussed by many authors (Smirnov, 1996; Kotov, 2013; Neretina \& Kotov, 2015;

494 Neretina et al., 2018), and this feature seems dubious for a reliable discrimination of any

495 subgenera. The same situation concerns the proportions of body and postabdomen. Another

496 strong defect of such classification (Hudec, 2010) is that one ignores completely any Non-

497 European Alonella taxa.

498

In fact, morphological differences between the best known Alonella species (Smirnov,

499

1996) are less expressed than those between Pleuroxus s.1. All attempts to subdivide the latter

500

genus into several genera or subgenera by morphological criteria are controversial due to the

501 mixing of morphological characters in the different taxa (Smirnov, 1996; Chiambeng \& Dumont,

502 2004). The taxonomic challenges for Alonella and Pleuroxus must be resolved with a

503 combination of morphological and genetic data (integrative approach), such studies are known

504 for different microcrustacean groups (Karanovic \& Cooper, 2012; Montoliu-Elena, Elías-

505 Gutiérrez \& Silva-Briano, 2019; Ni et al., 2019). Among the inter-generic subdivisions based on

506 morphological characters carried out in the last two decades for any genera of the subfamily

507 Chydorinae, only attempts to subdivide Disparalona s.l. may be considered successful due to the

508 large number of reliable diagnostic features (Neretina et al., 2018, 2019). In general, since the

509 time of Smirnov (1996), morphological taxonomy of Chydorinae is poorly developed. For the 
510 latter, the morphological evidence is at its resolution limit, and such studies need to be

511 coordinated with molecular studies.

512

513

\section{Conclusions}

514

515

Our study reveals a high cryptic diversity within the genus Alonella across the Northern

516 Hemisphere. Some of detected main clades have wide ranges across the Old World (and even in

517 the New World), others clades have more restricted ranges, or are likely endemics. Our results

518 could be the basis for subsequent morphological study of Alonella, formal description of new

519 taxa and subsequent biogeographical analyses. Thus, biogeographic study is possible for even the

520 smallest of water fleas, as it was also demonstrated for other minute animals, like rotiferans

521 (Cieplinski, Weisse \& Obertegger, 2017; Mills et al., 2017) or ostracods (Hiruta et al., 2016). In

522 this sense, "Little pigeons can carry great messages".

523

524

Data availability

525

DNA sequences were submitted to NCBI GenBank resulting in the following accession

526

numbers MN608113-MN608151 and MN598677-MN598759.

527

528

\section{Acknowledgments}


530 Babenko, E.I. Bekker, F.E. Fedosov, A.S. Golubtsov, F.V. Kazansky, B.F. Khassanov, N.M.

531 Klimovskiy, N.M. Korovchinsky, N.A. Kuznetsova, O.A. Krylovich, E.S. Preobrazhenskaya,

532 L.V. Razumovsky, V.L. Razumovsky, A.B. Savinetsky, L.E. Savinetskaya, D.J. Taylor, A.V.

533 Tchabovsky, E.I. Zuykova for ethanol-fixed samples with Alonella, H.G. Jeong for help during

534 AAK's sampling in South Korea, A.A. Darkov for help during AAN stay in Ethiopia. Special

535 thanks to Prof. A. Petrusek for organization of molecular analysis of some specimens in Charles

536 University in Prague. Also, we thank S.I. Metelev and A.N. Nekrasov for their assistance to

537 ANN during SEM works. All SEM works were carried out at the Joint Usage Center

538 "Instrumental Methods in Ecology" (A.N. Severtsov Institute of Ecology and Evolution of

539 Russian Academy of Sciences).

540

541

Funding

542

ANN, DPK, AAK supported exclusively by the Russian Science Foundation (project №

18-14-00325) (http://www.rscf.ru/en/). VS has no specific funding support.

544

545

Author Contributions Statement

546

AAK, ANN, DPK, VS wrote the main manuscript, AN prepared Figure 1, DK and AK

547 prepared figures 2-5 and supplement figures. All authors reviewed the manuscript. 


\section{8}

549

\section{Competing Interests}

The authors declare that they have no competing interests. 
551

552

553 Quantifying the components of underestimation. Global Ecology and Biogeography 14(5): 455-

554468.

555

556

557 Cladocera: Chydoridae) from the Ecuadorian Andes. Zootaxa 4290(3): 1-11.

558

559

560

561

562

563

$564276-282$.

565

DOI 10.1016/j.virol.2013.07.032

566

Bekker EI, Kotov AA, Taylor DJ. 2012. A revision of the subgenus Eurycercus

567 (Eurycercus) Baird, 1843 emend. nov. (Cladocera: Eurycercidae) in the Holarctic with the

568 description of a new species from Alaska. Zootaxa 3206(1): 1-40.

569
DOI 10.11646/zootaxa.3206.1.1 
571 high cryptic diversity in the North Eurasian Moina species (Crustacea: Cladocera). PLoS ONE

572 11(8): e0161737.

573

DOI 10.1371/journal.pone.0161737

574

Bekker EI, Karabanov DP, Galimov YR, Haag CR, Neretina TV, Kotov AA. 2018.

575 Phylogeography of Daphnia magna Straus (Crustacea: Cladocera) in Northern Eurasia: Evidence

576 for a deep longitudinal split between mitochondrial lineages. PLoS ONE 13(3): e0194045.

577 DOI 10.1371/journal.pone.0194045

Belyaeva M, Taylor DJ. 2009. Cryptic species within the Chydorus sphaericus species

complex (Crustacea: Cladocera) revealed by molecular markers and sexual stage morphology.

Molecular Phylogenetics and Evolution 50(3): 534-546.

581

DOI 10.1016/j.ympev.2008.11.007

582

Blaxter M, Mann J, Chapman T, Thomas F, Whitton C, Floyd R, Abebe E. 2005.

Defining operational taxonomic units using DNA barcode data. Philosophical Transactions of

584 the Royal Society B: Biological Sciences 360(1462): 1935-1943.

585

DOI 10.1098/rstb.2005.1725

586

Bolstad WM. 2007. Introduction to Bayesian statistics. 2nd ed. Wiley-Interscience.

587 Boratyn GM, Camacho C, Cooper PS, Coulouris G, Fong A, Ma N, Madden TL, 
589 2013. BLAST: a more efficient report with usability improvements. Nucleic Acids Research

590 41(W1): W29-W33.

591

DOI 10.1093/nar/gkt282

592

Bouckaert R, Vaughan TG, Barido-Sottani J, Duchêne S, Fourment M,

593

Gavryushkina A, Heled J, Jones G, Kühnert D, De Maio N, Matschiner M, Mendes FK,

594

Müller NF, Ogilvie HA, du Plessis L, Popinga A, Rambaut A, Rasmussen D, Siveroni I, 595

Suchard MA, Wu C-H, Xie D, Zhang C, Stadler T, Drummond AJ. 2019. BEAST 2.5: An

596

advanced software platform for Bayesian evolutionary analysis. PLoS Computational Biology

597

15(4): e 1006650.

598

DOI 10.1371/journal.pcbi.1006650

599

Čandek K, Kuntner M. 2015. DNA barcoding gap: reliable species identification over

600

morphological and geographical scales. Molecular Ecology Resources 15(2): 268-277.

601

DOI 10.1111/1755-0998.12304

602

Chiambeng GY, Dumont HJ. 2004. The genus Pleuroxus Baird, 1843 (Crustacea:

603

Anomopoda: Chydoridae) in Cameroon, Central-West Africa. Annales de Limnologie 40(3):

604 $211-229$.

605

DOI 10.1051/limn/2004019 
607 Ctenopoda and Cyclestherida) of the rain forests of Cameroon, West Africa: low abundances,

608 few endemics and a boreal-tropical disjunction. Journal of Biogeography 32: 1611-1620.

609 DOI 10.1111/j.1365-2699.2005.01280.x

611 (Rotifera, Monogononta): morphological and genetic evidence. Hydrobiologia 796(1): 145-159. DOI 10.1007/s10750-016-2781-z in Ecology and Evolution 3(3): 457-465.

DOI 10.1111/j.2041-210X.2011.00176.x

Hebert PD. 2007. Biological identifications through DNA barcodes: the case of the Crustacea.

DOI 10.1139/f07-008 
624

Dlouhá S, Thielsch A, Kraus RHS, Seda J, Schwenk K, Petrusek A. 2010. Identifying

625 hybridizing taxa within the Daphnia longispina species complex: a comparison of genetic

626 methods and phenotypic approaches. Hydrobiologia 643(1): 107-122.

627

DOI $10.1007 / \mathrm{s} 10750-010-0128-8$

628

Drummond AJ, Ho SY, Phillips MJ, Rambaut A. 2006. Relaxed phylogenetics and

629

dating with confidence. PLoS Biologyl 4(5): e88.

630

DOI 10.1371/journal.pbio.0040088

631

Drummond AJ, Suchard MA, Xie D, Rambaut A. 2012. Bayesian phylogenetics with

632

BEAUti and the BEAST 1.7. Molecular Biology and Evolution 29(8): 1969-1973.

633 DOI 10.1093/molbev/mss075

634

Dumont HJ. 1981. Cladocera and free-living Copepoda from the Fouta Djalon and

635

adjacent mountain ares in West Africa. Hydrobiologia 85 (2): 97-116.

636

Elías-Gutiérrez M, Valdez-Moreno M, Topan J, Young MR, Cohuo-Colli JA. 2018.

637

Improved protocols to accelerate the assembly of DNA barcode reference libraries for freshwater

638 zooplankton. Ecology and Evolution 8(5): 3002-3018.

639

DOI $10.1002 /$ ece 3.3742

640

Faustova M. 2017. Phylogeny, phylogeography and taxonomy of selected members of

641 the family Bosminidae. D. Phil. Thesis, Univerzita Karlova, Př́rodovědecká fakulta. 
642

Faustova M, Sacherová V, Svensson JE, Taylor DJ. 2011. Radiation of European

643 Eubosmina (Cladocera) from Bosmina (E.) longispina - concordance of multipopulation

644 molecular data with paleolimnology. Limnology and Oceanography 56(2): 440-450.

645

DOI 10.4319/10.2011.56.2.0440

646

Forró L, Korovchinsky NM, Kotov AA, Petrusek A. 2008. Global diversity of

647 cladocerans (Cladocera; Crustacea) in freshwater. Hydrobiologia 595: 177-184.

648

DOI 10.1007/978-1-4020-8259-7_19

649

Frey DG. 1982. Questions concerning cosmopolitanism in Cladocera. Archiv für

650

Hydrobiologie 93(4): 484-502.

651

Frey DG. 1987. The non-cosmopolitanism of chydorid Cladocera: implications for

652

biogeography and evolution. In: Gore RH and Heck KL (eds). Crustacean biogeography

653

(Crustacean issues 4): 237-256.

654

Fu YX. 1997. Statistical tests of neutrality of mutations against population growth,

655

hitchhiking and background selection. Genetics 147(2): 915-925.

656

Fujisawa T, Barraclough TG. 2013. Delimiting species using single-locus data and the

657 Generalized Mixed Yule Coalescent approach: a revised method and evaluation on simulated

658 data sets. Systematic Biology 62(5): 707-724.

659

DOI 10.1093/sysbio/syt033 
661 multilocus species delimitation using Bayesian model comparison and rooted triplets. Systematic

662 Biology 65(5): 759-771.

663 DOI 10.1093/sysbio/syw028 group (Crustacea: Cladocera: Chydoridae). Zootaxa 4532(4): 451-482. of London. Series B: Biological Sciences 270(suppl_1): S96-S99.

677 through DNA barcodes. Plos Biology 2(10): e312. 
680

681

682

683

684

685

686

687

688

689

690

691

692

693

694

695

696

697

data. Molecular Biology and Evolution 27(3): 570-580.

DOI 10.1093/molbev/msp274

Hiruta SF, Kobayashi N, Katoh T, Kajihara,H. 2016. Molecular phylogeny of

cypridoid freshwater Ostracods (Crustacea: Ostracoda), inferred from 18S and 28S rDNA

sequences. Zoological Science 33(2): 179-185.

DOI $10.2108 /$ zs 150103

Hoang DT, Chernomor O, Von Haeseler A, Minh BQ, Vinh LS. 2018. UFBoot2:

improving the ultrafast bootstrap approximation. Molecular Biology and Evolution 35(2): 518522.

DOI 10.1093/molbev/msx281

Hudec I. 2010. Anomopoda, Ctenopoda, Haplopoda, Onychopoda (Crustacea:

Branchiopoda). Fauna Slovenska III. Bratislava: VEDA.

Huemer P, Mutanen M, Sefc KM, Hebert PD. 2014. Testing DNA barcode

performance in 1000 species of European Lepidoptera: large geographic distances have small

genetic impacts. PLoS One 9(12): e115774.

DOI 10.1371/journal.pone.0115774

Huson DH, Scornavacca C. 2012. Dendroscope 3: an interactive tool for rooted

phylogenetic trees and networks. Systematic Biology 61(6): 1061-1067.

Peer] reviewing PDF | (2020:09:52695:2:0:CHECK 18 Dec 2020) 
DOI 10.1111/j.1096-3642.2006.00214.x

703 Ishida S, Taylor DJ. 2007. Quaternary diversification in a sexual Holarctic zooplankter,

704

705

706

707

708

709

710

711

712

713

714

715 716

Daphnia galeata. Molecular Ecology, 16: 569-582.

DOI 10.1111/j.1365-294X.2006.03160.x

Jeffery NW, Elías-Gutiérrez M, Adamowicz SJ. 2011. Species diversity and

phylogeographical affinities of the Branchiopoda (Crustacea) of Churchill, Manitoba, Canada.

PLoS One 6(5): e18364.

DOI 10.1371/journal.pone.0018364

Jones G. 2017. Algorithmic improvements to species delimitation and phylogeny

estimation under the multispecies coalescent. Journal of Mathematical Biology 74(1-2): 447467.

DOI 10.1007/s00285-016-1034-0

Kalyaanamoorthy S, Minh BQ, Wong TK, von Haeseler A, Jermiin LS. 2017.

ModelFinder: fast model selection for accurate phylogenetic estimates. Nature Methods 14(6): $587-589$. 
719 Multi-rate Poisson tree processes for single-locus species delimitation under maximum

720 likelihood and Markov chain Monte Carlo. Bioinformatics 33(11): 1630-1638.

721 DOI 10.1093/bioinformatics/btx025

722 Karabanov DP, Bekker EI, Shiel RJ, Kotov AA. 2018. Invasion of a Holarctic

planktonic cladoceran Daphnia galeata Sars (Crustacea: Cladocera) in the Lower Lakes of South

724 Australia. Zootaxa 4402(1): 136-148.

725

DOI 10.11646/zootaxa.4402.1.6

726 Karanovic T, Cooper SJ. 2012. Explosive radiation of the genus Schizopera on a small subterranean island in Western Australia (Copepoda: Harpacticoida): unravelling the cases of cryptic speciation, size differentiation and multiple invasions. Invertebrate Systematics 26(2):

729 115-192.

730 DOI 10.1071/IS11027 Kartavtsev YP. 2018. Barcode index number, taxonomic rank and modes of speciation: examples from fish. Mitochondrial DNA Part A 29(4): 535-542. DOI 10.1080/24701394.2017.1315570 Katoh K, Standley DM. 2016. A simple method to control over-alignment in the 
DOI 10.1093/bioinformatics/btw108

737

Kotov AA. 2013. Morphology and phylogeny of the Anomopoda (Crustacea: Cladocera)

738 Moscow: KMK Scientific press Ltd.

739

Kotov AA. 2016. Faunistic complexes of the Cladocera (Crustacea, Branchiopoda) of

740 Eastern Siberia and the Far East of Russia. Biology Bulletin 43(9): 970-987.

741

DOI 10.1134/S1062359016090041

742

Kotov AA, Taylor DJ. 2010. A new African lineage of the Daphnia obtusa group

743 (Cladocera: Daphniidae) disrupts continental vicariance patterns. Journal of Plankton Research

744 32(6): 937-949.

745

DOI 10.1093/plankt/fbq018

746

Kotov AA, Taylor DJ. 2019. Contrasting endemism in pond-dwelling cyclic

747

748

9(1): $1-10$.

749

DOI 10.1093/plankt/fbq018

750

Kotov AA, Ishida S, Taylor DJ. 2009. Revision of the genus Bosmina (Cladocera:

751

Bosminidae), based on evidence from male morphological characters and molecular phylogenies.

752

Zoological Journal of the Linnean Society 156(1): 1-51.

753

DOI 10.1111/j.1096-3642.2008.00475.x

754 
757 Palaearctic: taxonomy, phylogeny and phylogeography. Zoological Journal of the Linnean

758 Society, On-line First.

DOI 10.1093/zoolinnean/zlaa046 DOI 10.4081/jlimnol.2013.s2.e6

35(6): 1547-1549. 
775 al. (2006). Systematic Biology 58(4): 439-442.

776

DOI 10.1093/sysbio/syp039

777

Maddison WP, Wiens JJ. 1997. Gene trees in species trees. Systematic Biology 46:

$778523-536$.

779

DOI 10.1093/sysbio/46.3.523

780

Marková S, Dufresne F, Rees DJ, Černý M, Kotlík P. 2007. Cryptic intercontinental

781

colonization in water fleas Daphnia pulicaria inferred from phylogenetic analysis of

782

mitochondrial DNA variation. Molecular Phylogenetics and Evolution 44(1): 42-52.

783

DOI 10.1016/j.ympev.2006.12.025

784

Meier R, Shiyang K, Vaidya G, Ng PK. 2006. DNA barcoding and taxonomy in

785

Diptera: a tale of high intraspecific variability and low identification success. Systematic Biology

786

55(5): 715-728.

787

DOI 10.1080/10635150600969864

788

Millette KL, Xu S, Witt JD, Cristescu ME. 2011. Pleistocene-driven diversification in

789

freshwater zooplankton: Genetic patterns of refugial isolation and postglacial recolonization in

790

Leptodora kindtii (Crustacea, Cladocera). Limnology and Oceanography 56(5): 1725-1736.

791

DOI 10.4319/10.2011.56.5.1725 
793 KH, ... \& Welch DBM. 2017. Fifteen species in one: deciphering the Brachionus plicatilis

794 species complex (Rotifera, Monogononta) through DNA taxonomy. Hydrobiologia 796(1): 3979558.

796

DOI 10.1007/s10750-016-2725-7

797

Molloy EK, Warnow T. 2018. To include or not to include: the impact of gene filtering

798

799

800

801

802

803

804

805

806

807

808

809

810 on species tree estimation methods. Systematic Biology 67(2): 285-303.

DOI 10.1093/sysbio/syx077

Montoliu-Elena L, Elías-Gutiérrez M, Silva-Briano M. 2019. Moina macrocopa

(Straus, 1820): a species complex of a common Cladocera, highlighted by morphology and DNA barcodes. Limnetica 38(1): 253-277.

DOI 10.23818/limn.38.19

Nei M, Kumar S. 2000. Molecular evolution and phylogenetics. Oxford university press. Neretina AN, Kotov AA. 2015. A new species of Acroperus Baird, 1843 (Cladocera:

Chydoridae) from Africa. Zootaxa 4039(4): 516-528.

DOI 10.11646/zootaxa.4039.4.2

Neretina AN, Garibian PG, Sinev AY, Kotov AA. 2018. Diversity of the subgenus

Disparalona (Mixopleuroxus) Hudec, 2010 (Crustacea: Cladocera) in the new and old world.

Journal of Natural History 52(3-4): 155-205. 
813 record of Disparalona hamata (Birge, 1879) (Cladocera: Chydoridae) in phytotelmata of

814 Tillandsia aguascalentensis Gardner, 1984 (Poales: Bromeliaceae). Zootaxa 4567(2): 347-357.

DOI 10.11646/zootaxa.4567.2.7

816 Nguyen LT, Schmidt HA, Von Haeseler A, Minh BQ. 2015. IQ-TREE: a fast and

817 effective stochastic algorithm for estimating maximum-likelihood phylogenies. Molecular

818 Biology and Evolution 32(1): 268-274.

DOI 10.1093/molbev/msu300

821 diversity and regional distribution of Moina (Crustacea: Cladocera) in China. Molecular

822 Phylogenetics and Evolution 134: 87-98.

823

DOI 10.1016/j.ympev.2019.02.007

824

Petrusek A, Černy M, Audenaert E. 2004. Large intercontinental differentiation of

825 Moina micrura (Crustacea: Anomopoda): one less cosmopolitan cladoceran? Hydrobiologia

826 526: 73-81.

827

DOI 10.1023/B:HYDR.0000041612.08425.f0 
829 taxonomic reappraisal of the European Daphnia longispina complex (Crustacea, Cladocera,

830 Anomopoda). Zoologica Scripta 37: 507-519.

831

DOI 10.1111/j.1463-6409.2008.00336.x

832

Pons J, Barraclough TG, Gomez-Zurita J, Cardoso A, Duran DP, Hazell S, ... \&

833 Vogler AP. 2006. Sequence-based species delimitation for the DNA taxonomy of undescribed

834 insects. Systematic Biology 55(4): 595-609.

835

DOI 10.1080/10635150600852011

836

Popova EV, Petrusek A, Koř́nek V, Mergeay J, Bekker EI, Karabanov DP,

837

Galimov YR, Neretina TV, Taylor DJ, Kotov AA. 2016. Revision of the Old World Daphnia

838

(Ctenodaphnia) similis group (Cladocera: Daphniidae). Zootaxa 4161(1): 1-40.

839

DOI 10.11646/zootaxa.4161.1.1

840

Posada D, Buckley TR. 2004. Model selection and model averaging in phylogenetics:

841 advantages of Akaike information criterion and Bayesian approaches over likelihood ratio tests.

842 Systematic Biology 53(5): 793-808.

843

DOI 10.1080/10635150490522304

844

Posada D, Crandall KA. 2001. Selecting the best-fit model of nucleotide substitution.

845 Systematic Biology 50(4): 580-601.

846

DOI $10.1080 / 10635150118469$ 
848 environmental DNA sequence data. Methods in Ecology and Evolution 3(1): 1-11.

DOI 10.1111/j.2041-210X.2011.00122.x

850 Prosser S, Martínez-Arce A, Elías-Gutiérrez M. 2013. A new set of primers for COI

851

852

853

854

855

856

857

858

859

860

861

862

863

864

865

DOI 10.1111/1755-0998.12132

Puillandre N, Lambert A, Brouillet S, \& ACHAZ, G. 2012. ABGD, Automatic

Barcode Gap Discovery for primary species delimitation. Molecular Ecology 21(8): 1864-1877.

DOI 10.1111/j.1365-294X.2011.05239.x

Ramos-Onsins SE, Rozas J. 2002. Statistical properties of new neutrality tests against population growth. Molecular Biology and Evolution 19(12): 2092-2100.

DOI 10.1093/oxfordjournals.molbev.a004034

Ramírez-Soriano A, Ramos-Onsins SE, Rozas J, Calafell F, Navarro A. 2008.

Statistical power analysis of neutrality tests under demographic expansions, contractions and bottlenecks with recombination. Genetics 179(1): 555-567.

DOI 10.1534/genetics.107.083006

Rambaut A, Drummond AJ, Xie D, Baele G, Suchard MA. 2018. Posterior

summarization in Bayesian phylogenetics using Tracer 1.7. Systematic Biology 67(5): 901. 
DOI 10.1093/sysbio/syy032

867 Ratnasingham S, Hebert PD. 2013. A DNA-based registry for all animal species: the

868

869

870

871

872

873

874

875

876

877

878

879

880

881

882

883

884

Barcode Index Number (BIN) system. PloS one 8(7): e66213.

DOI 10.1371/journal.pone.0066213

Reid NM, Carstens BC. 2012. Phylogenetic estimation error can decrease the accuracy

of species delimitation: a Bayesian implementation of the general mixed Yule-coalescent model.

BMC Evolutionary Biology 12(1): 196.

DOI 10.1186/1471-2148-12-196

Rey J, Saint-Jean L. 1968. Les Cladocères (Crustacés, Branchiopodes) du Tchad.

Cahiers ORSTOM, série Serie Hydrobiologie 2(3/4): 79-118.

Rokas A, Williams BL, King N, Carroll SB. 2003. Genome-scale approaches to resolving incongruence in molecular phylogenies. Nature 425(6960): 798-804.

DOI 10.1038/nature02053

Rozas J, Ferrer-Mata A, Sánchez-DelBarrio JC, Guirao-Rico S, Librado P, Ramos-

Onsins SE, Sánchez-Gracia A. 2017. DnaSP 6: DNA sequence polymorphism analysis of large data sets. Molecular Biology and Evolution 34(12): 3299-3302.

DOI 10.1093/molbev/msx248

Sacherová V, Hebert PDN. 2003. The evolutionary history of the Chydoridae

(Crustacea: Cladocera). Biological Journal of the Linnean Society 79: 629-643. 
885

886

887

888

889

890

891

892

893

894

895

896

897

898

899

900

901

902

DOI 10.1046/j.1095-8312.2003.00216.x

Sarver BA, Pennell MW, Brown JW, Keeble S, Hardwick KM, Sullivan J, Harmon

LJ. 2019. The choice of tree prior and molecular clock does not substantially affect phylogenetic inferences of diversification rates. PeerJ 7: e6334.

DOI $10.7717 /$ peerj.6334

Schwenk K, Sand A, Boersma M, Brehm M, Mader E, Offerhaus D, Spaak P. 1998.

Genetic markers, genealogies and biogeographic patterns in the Cladocera. Aquatic Ecology

32(1): $37-51$.

DOI 10.1023/A:1009939901198

Schwentner M, Rabet N, Richter S, Giribet G, Padhye S, Cart JF, ... \& Rogers DC.

2020. Phylogeny and Biogeography of Spinicaudata (Crustacea: Branchiopoda). Zoological

Studies 59(44): 2020-59.

DOI 10.6620/ZS.2020.59-44

Scornavacca C, Zickmann F, Huson DH. 2011. Tanglegrams for rooted phylogenetic

trees and networks. Bioinformatics 27(13): i248-i256.

DOI 10.1093/bioinformatics/btr210

Simon C, Frati F, Beckenbach A, Crespi B, Liu H, Flook P. 1994. Evolution,

weighting, and phylogenetic utility of mitochondrial gene sequences and a compilation of 
903 conserved polymerase chain reaction primers. Annals of the entomological Society of America

904 87(6): 651-701.

$905 \quad$ DOI $10.1093 /$ aesa/87.6.651

906 Sinev AY, Karabanov DP, Kotov AA. 2020. A new North Eurasian species of the

907 Alona affinis complex (Cladocera: Chydoridae). Zootaxa 4767(1): 115-137.

908

DOI 10.11646/zootaxa.4767.1.5

909

Smirnov NN. 1971. Chydoridae fauni mira. Fauna SSSR. Rakoobraznie 1(2): 1-531.

910

Smirnov NN.1996. Cladocera: the Chydorinae and Sayciinae (Chydoridae) of the world.

911 Guides to the identification of the microivertebrates of the Continental Waters of the world. SPB

912 Academic Publishing, Amsterdam 11: 1-197.

913 Smirnov NN, Kotov AA. 2010. The morphological radiation of setae in the Cladocera

914 (Crustacea) and their potential for morphogenesis. International Review of Hydrobiology 95(6):

$915 \quad 482-519$.

916

DOI 10.1002/iroh.201011244

917

Steel M, McKenzie A. 2001. Properties of phylogenetic trees generated by Yule-type

918 speciation models. Mathematical Biosciences 170(1): 91-112.

919

DOI 10.1016/S0025-5564(00)00061-4

920

Sukumaran J, Knowles LL. 2017. Multispecies coalescent delimits structure, not

921 species. Proceedings of the National Academy of Sciences 114(7): 1607-1612. 
922

DOI 10.1073/pnas.1607921114

923

Sweet AD, Boyd BM, Allen JM, Villa SM, Valim MP, Rivera-Parra JL, ... \&

924

Johnson KP. 2018. Integrating phylogenomic and population genomic patterns in avian lice

925 provides a more complete picture of parasite evolution. Evolution 72(1): 95-112.

926

DOI 10.1111/evo.13386

927

Tang CQ, Humphreys AM, Fontaneto D, Barraclough TG. 2014. Effects of

928

phylogenetic reconstruction method on the robustness of species delimitation using single-locus

929

data. Methods in Ecology and Evolution 5(10): 1086-1094.

930

DOI 10.1111/2041-210X.12246

931

Taylor DJ, Hebert PDN. 1993. Cryptic intercontinental hybridization in Daphnia

932

(Crustacea): the ghost of introductions past. Proceedings of the Royal Society of London, Series

933

B-Biological Sciences, 254: 163-168.

934

DOI 10.1098/rspb.1993.0141

935

Trifinopoulos J, Nguyen LT, von Haeseler A, Minh BQ. 2016. W-IQ-TREE: a fast

936

online phylogenetic tool for maximum likelihood analysis. Nucleic acids research 44(W1):

937

W232-W235.

938

DOI 10.1093/nar/gkw256 
940 fast assembly of multi-gene datasets with character set and codon information. Cladistics 27(2):

$941 \quad 171-180$.

942

DOI 10.1111/j.1096-0031.2010.00329.x

943

Van Damme K, Eggermont H. 2011. The Afromontane Cladocera (Crustacea:

944 Branchiopoda) of the Rwenzori (Uganda-DR Congo): taxonomy, ecology and biogeography.

945 Hydrobiologia 676(1): 57.

946

DOI 10.1007/s10750-011-0892-0

947

Vitecek S, Kučinić M, Previšić A, Živić I, Stojanović K, Keresztes L, Bálint

948

M, Hoppeler F, Waringer J, Graf W, Pauls SU. 2017. Integrative taxonomy by molecular

949

species delimitation: multi-locus data corroborate a new species of Balkan Drusinae micro-

950

endemics. BMC Evolutionary Biology 17(1): 129.

951

DOI 10.1186/s12862-017-0972-5

952

Warren DL, Geneva AJ, Lanfear R. 2017. RWTY (R We There Yet): an R package for

953

examining convergence of Bayesian phylogenetic analyses. Molecular Biology and Evolution

954 34(4): 1016-1020.

955

DOI 10.1093/molbev/msw279

956

Xu S, Hebert PDN, Kotov AA, Cristescu ME. 2009. The noncosmopolitanism

957

paradigm of freshwater zooplankton: insights from the global phylogeography of the predatory 
958 cladoceran Polyphemus pediculus (Linnaeus, 1761) (Crustacea, Onychopoda). Molecular

959 Ecology 18(24): 5161-5179.

960

DOI 10.1111/j.1365-294X.2009.04422.x

961

Xu L, Han BP, Van Damme K, Vierstraete A, Vanfleteren JR, Dumont HJ. 2011.

962

Biogeography and evolution of the Holarctic zooplankton genus Leptodora (Crustacea:

963 Branchiopoda: Haplopoda). Journal of Biogeography 38(2): 359-370.

964

DOI 10.1111/j.1365-2699.2010.02409.x

965

Yin M, Wan X, Ma X, Gießler S, Petrusek A, Griebel J, Hu W, Wolinska J. 2018.

966

Cytonuclear diversity and shared mitochondrial haplotypes among Daphnia galeata populations

967

separated by seven thousand kilometres. BMC Evolutionary Biology, 18(1): 130.

968

DOI 10.1186/s12862-018-1256-4

969

Zhang J, Kapli P, Pavlidis P, Stamatakis A. 2013. A general species delimitation

970

method with applications to phylogenetic placements. Bioinformatics 29(22): 2869-2876.

971

DOI 10.1093/bioinformatics/btt499

972

Zhang C, Rabiee M, Sayyari E, Mirarab S. 2018. ASTRAL-III: polynomial time

973

species tree reconstruction from partially resolved gene trees. BMC Bioinformatics 19(6): 153.

974

DOI 10.1186/s12859-018-2129-y

975

Zuykova EI, Simonov EP, Bochkarev NA, Abramov SA, Sheveleva NG, Kotov AA.

976

2018. Contrasting phylogeographic patterns and demographic history in closely related species 
977 of Daphnia longispina group (Crustacea: Cladocera) with focus on North-Eastern Eurasia. PLoS

978 ONE 13(11): $\mathrm{e} 0207347$.

$979 \quad$ DOI $10.1371 /$ journal.pone.0207347

980 


\section{Captions to figures}

982

983

Fig. 1. Alonella parthenogenetic females identified based on morphological

984 characters. General view and sculpture of valves of A. nana (A-B) (from Lake Glubokoe,

985 Moscow Area, Russia); A. exigua (C-D) (from Meertvoe Lake in the vicinities of Krasnaya

986 Pahra village, Moscow Area, Russia); A. excisa (E-F) (from the roadside mire, Yakutia

987 Republic, Russia). Scale bars: $0.1 \mathrm{~mm}$ for A, C, E, $0.02 \mathrm{~mm}$ for B, D, F.

988

989

Fig. 2. Maximum likelihood tree representing the diversity among phylogroups of

Alonella based on 16S data. The support values of individual nodes are based on bootstrap-test

991

UFBoot2.

992

993

Fig. 3. Maximum likelihood tree representing the diversity among phylogroups of

994

995

996

997

998

999
Fig. 4. Distribution of major Alonella clades (both original and sequences retrieved

from NCBI GenBank). The base map was from the open domain plain map available at

https://marble.kde.org/. 
1001

1002 Fig. 5. Summary of results of molecular species delimitation via different methods.

1003 The BI multi-locus tree is showed. Analyses referring to STACEY and "tr2" are based on multi-

1004 locus datasets; for further analytical details, see text. Dark grey indicates groups delimited by the

1005 different methods, and light grey the messing data Node supports are UFboot2 (ML) and

1006 posterior probabilities (BI), in percent.

1007 


\section{Figure 1}

Alonella parthenogenetic females identified based on morphological characters.

General view and sculpture of valves of $A$. nana (A-B) (from Lake Glubokoe, Moscow Area, Russia); A. exigua (C-D) (from Meertvoe Lake in the vicinities of Krasnaya Pahra village, Moscow Area, Russia); A. excisa (E-F) (from the roadside mire, Yakutia Republic, Russia).

Scale bars: $0.1 \mathrm{~mm}$ for $\mathrm{A}, \mathrm{C}, \mathrm{E}, 0.02 \mathrm{~mm}$ for $\mathrm{B}, \mathrm{D}, \mathrm{F}$. 

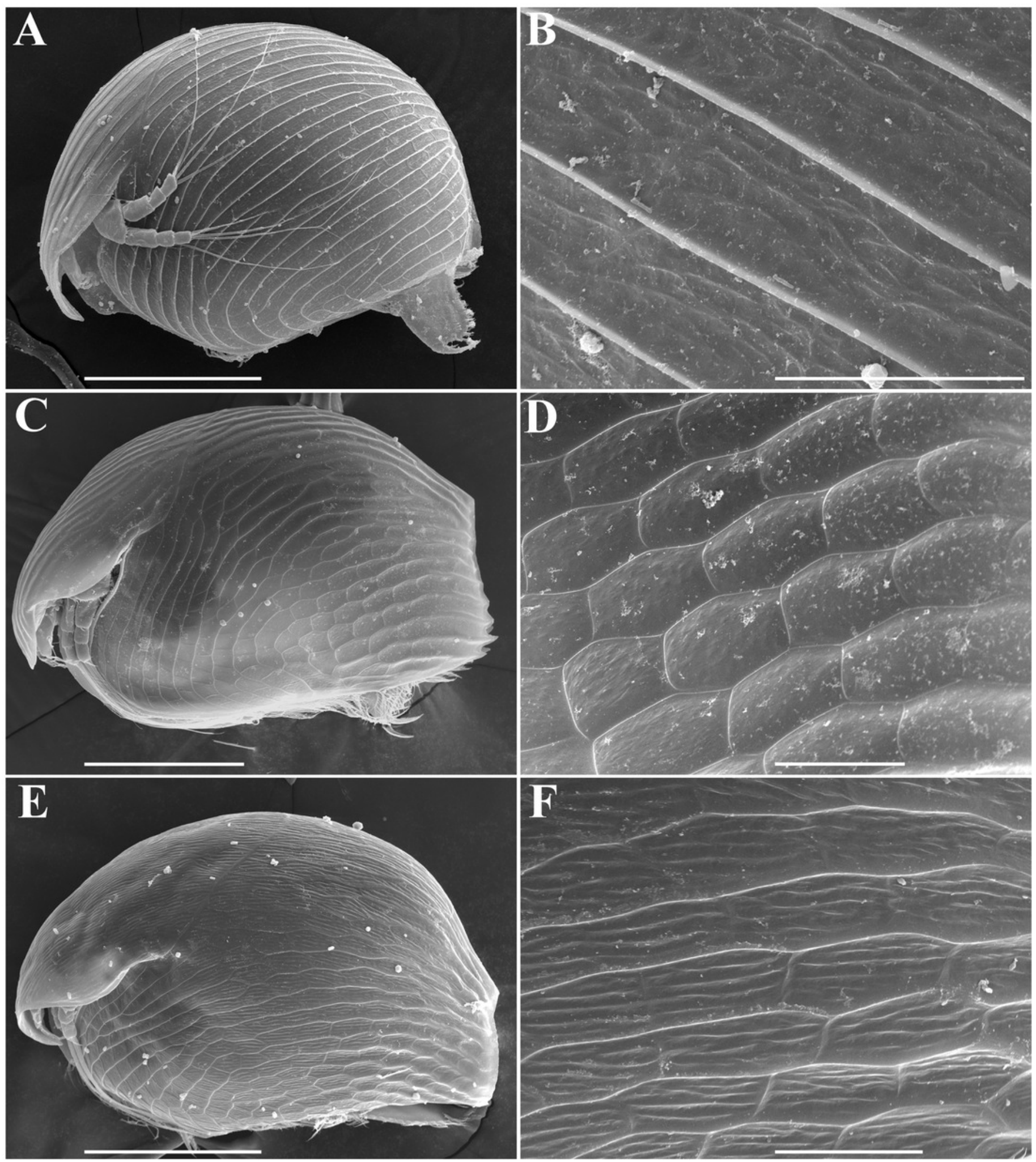
Figure 2

Maximum likelihood tree representing the diversity among phylogroups of Alonella based on 16S data.

The support values of individual nodes are based on bootstrap-test UFBoot2).

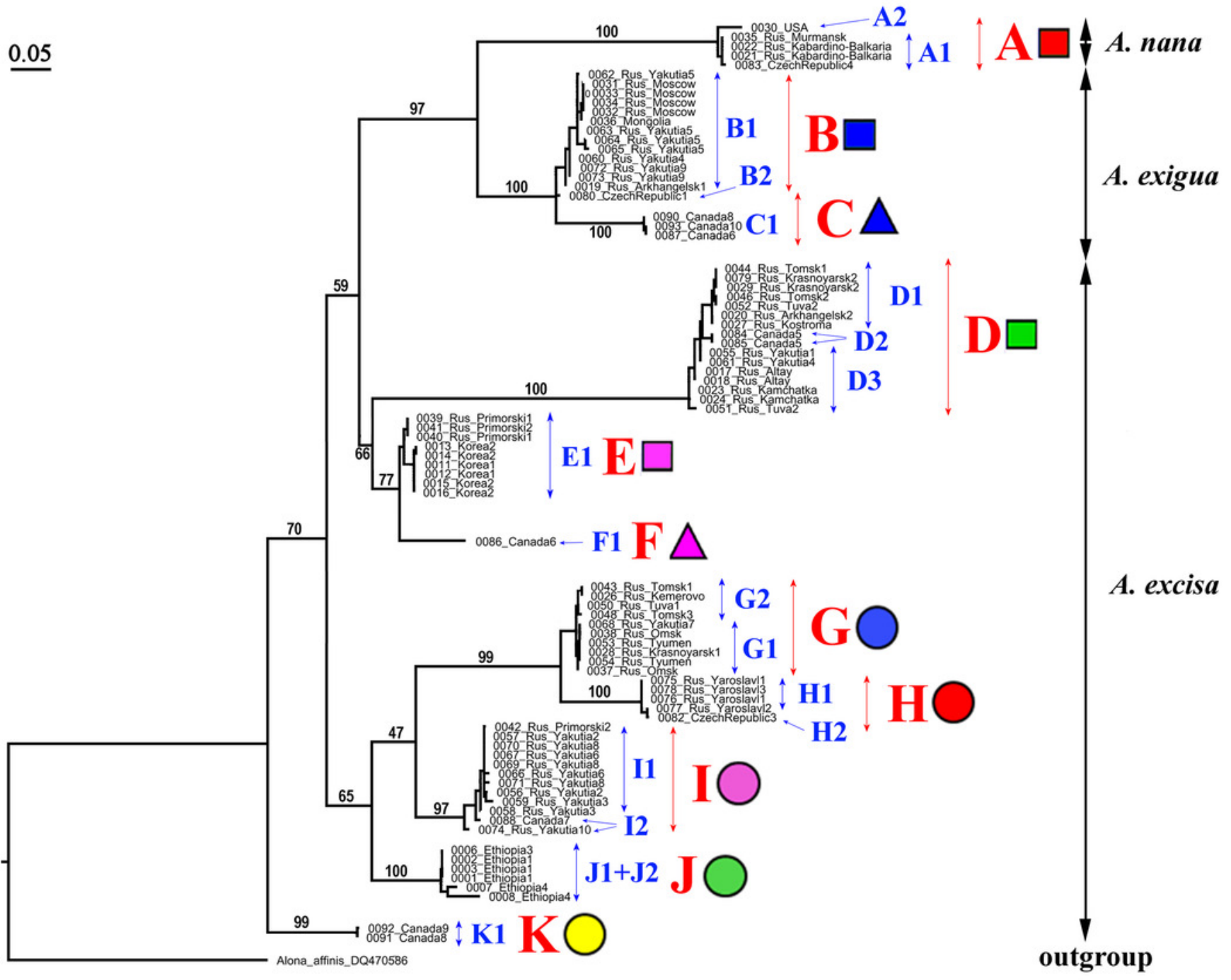


Figure 3

Maximum likelihood tree representing the diversity among phylogroups of Alonella based on COI data.

The support values of individual nodes are based on bootstrap-test UFBoot2.

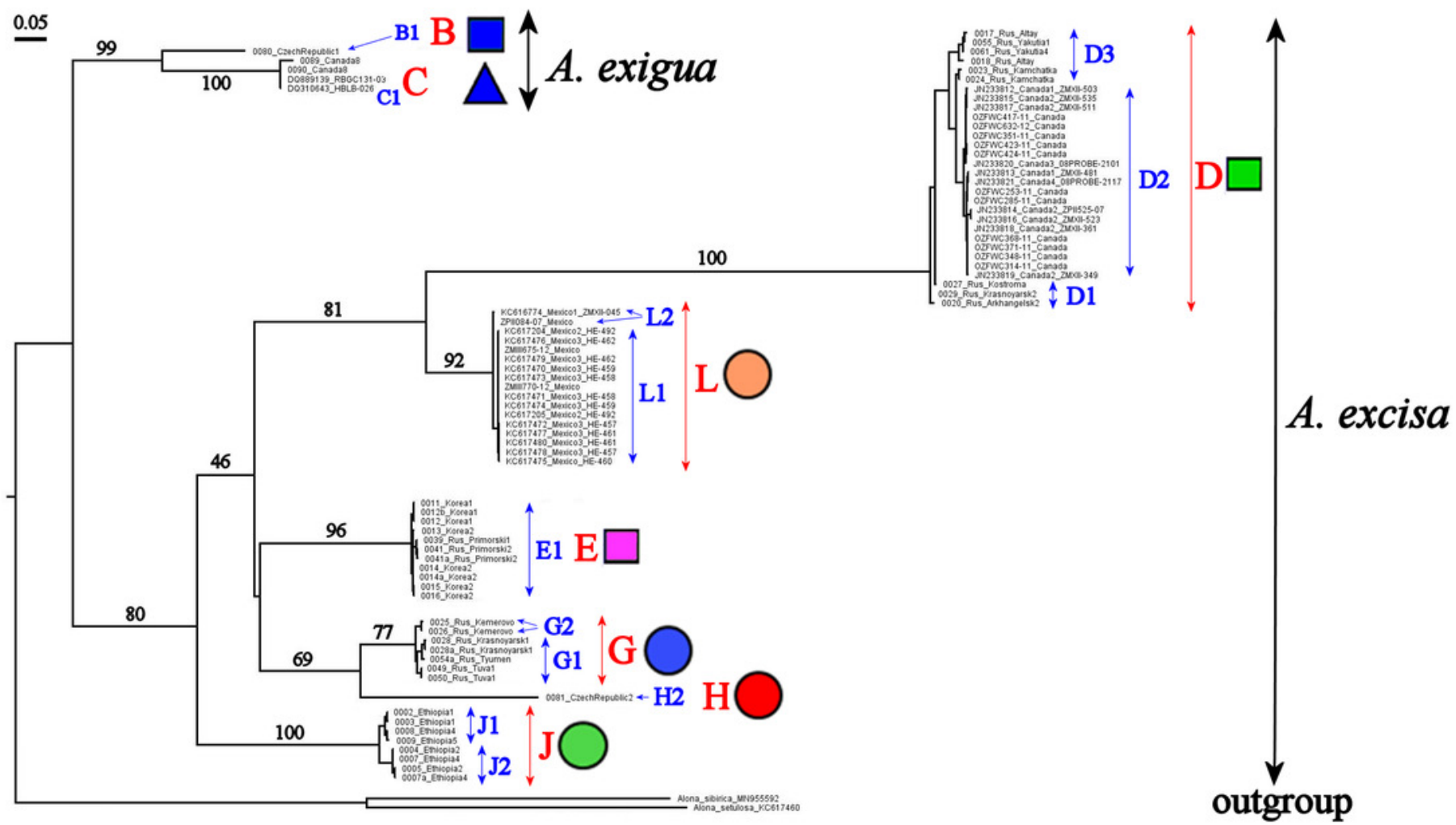


Figure 4

Distribution of major Alonella clades (both original and sequences retrieved from NCBI GenBank).

The base map was from the open domain plain map available at https://marble.kde.org/. 

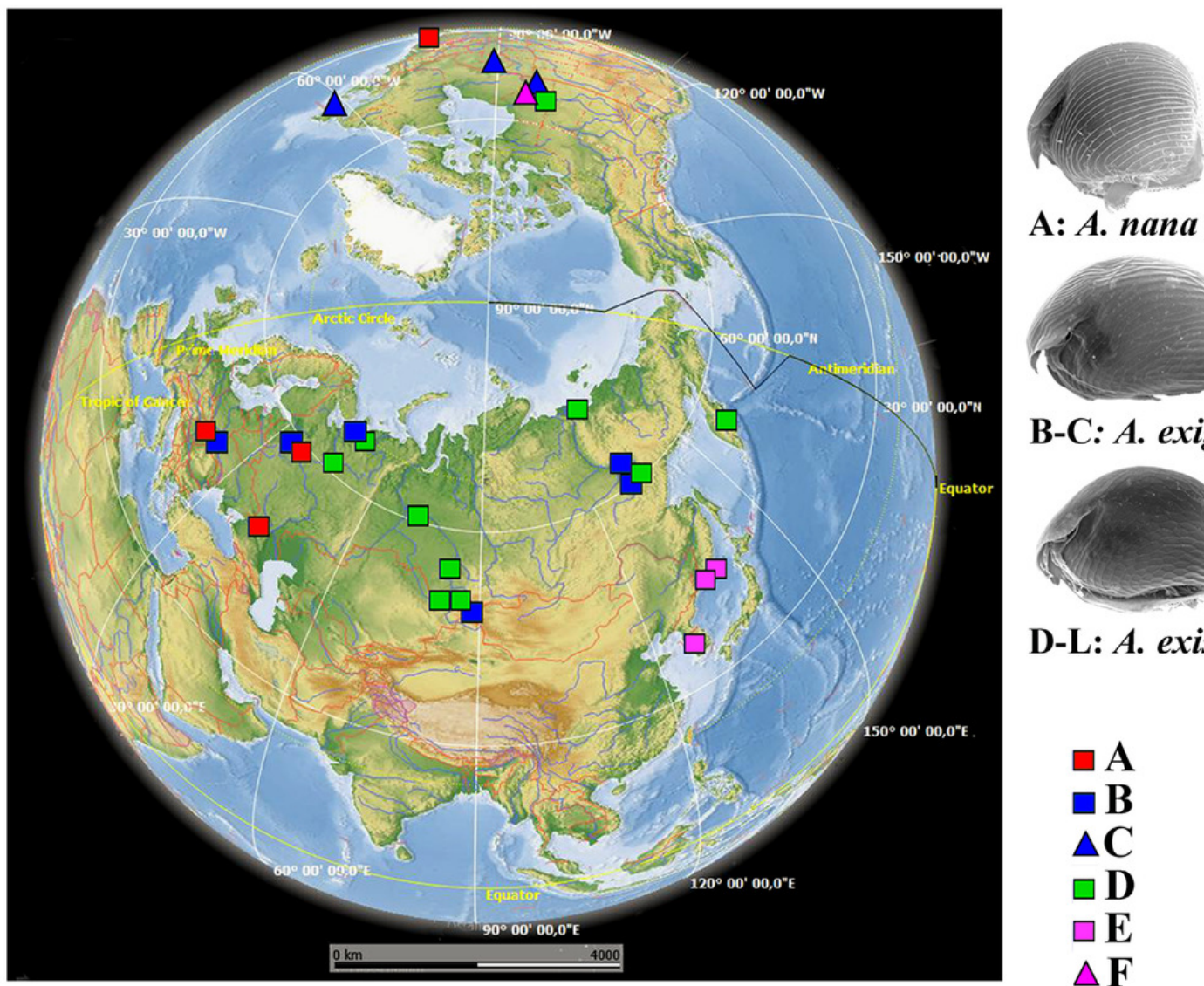

A: A. nana

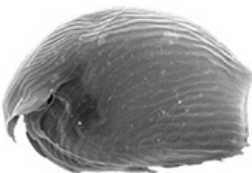

B-C: A. exigua
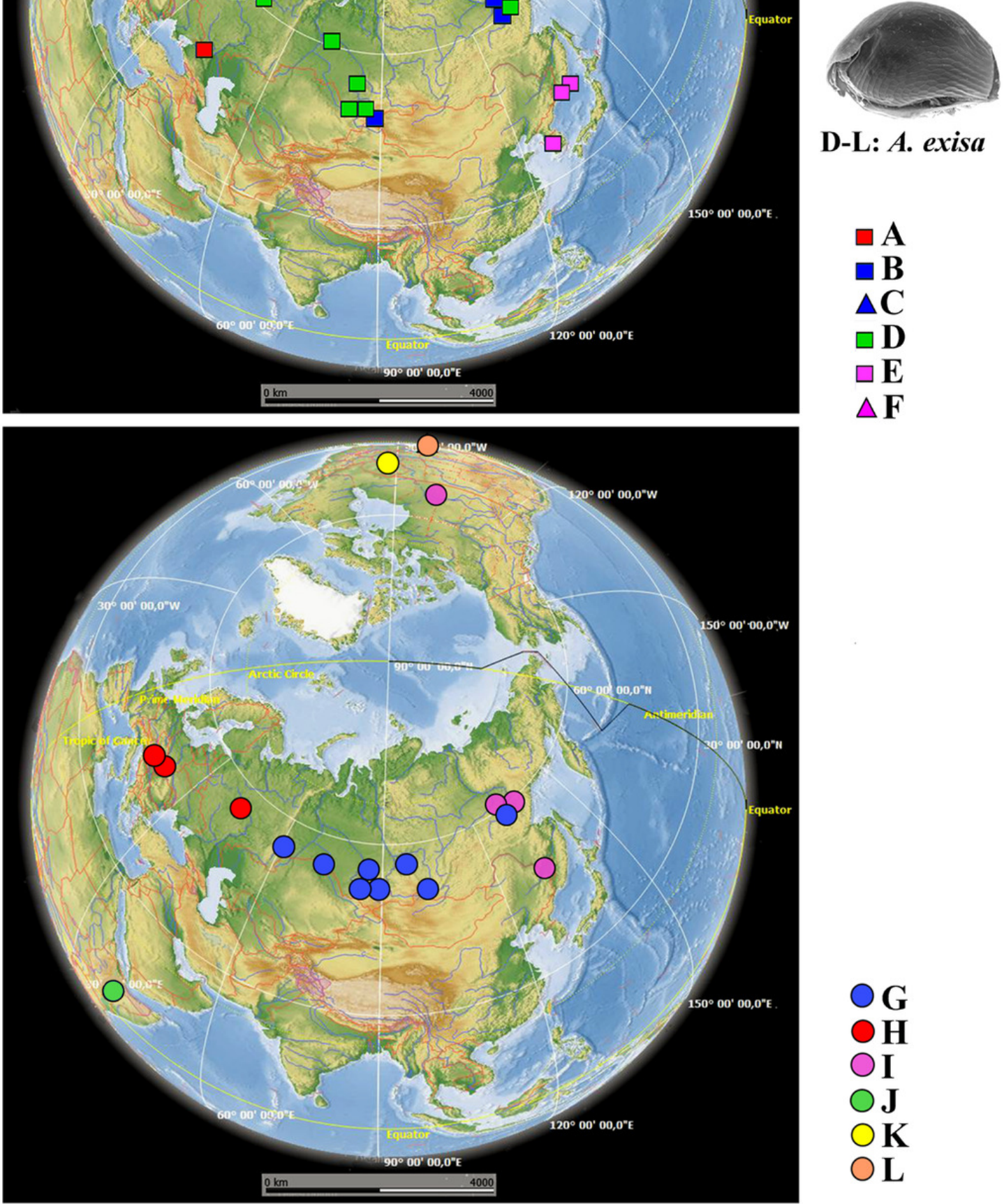

D-L: A. exisa

$\square \mathbf{A}$
$\square \mathbf{B}$
$\mathbf{\Delta C}$
$\square \mathbf{D}$
$\square \mathbf{E}$
$\triangle \mathbf{F}$

G

H

OI

$\bigcirc \mathbf{J}$

$\mathrm{OK}$

$\bigcirc \mathbf{L}$ 


\section{Figure 5}

Summary of results of molecular species delimitation via different methods.

The BI multi-locus tree is showed. Analyses referring to STACEY and "tr2" are based on multilocus datasets; for further analytical details, see text. Coloration indicates group membership of specimens; absence of coloration indicates missing data. Node supports are UFboot2 (ML) and posterior probabilities (BI), in percent. Grey color marked absent sequences. 

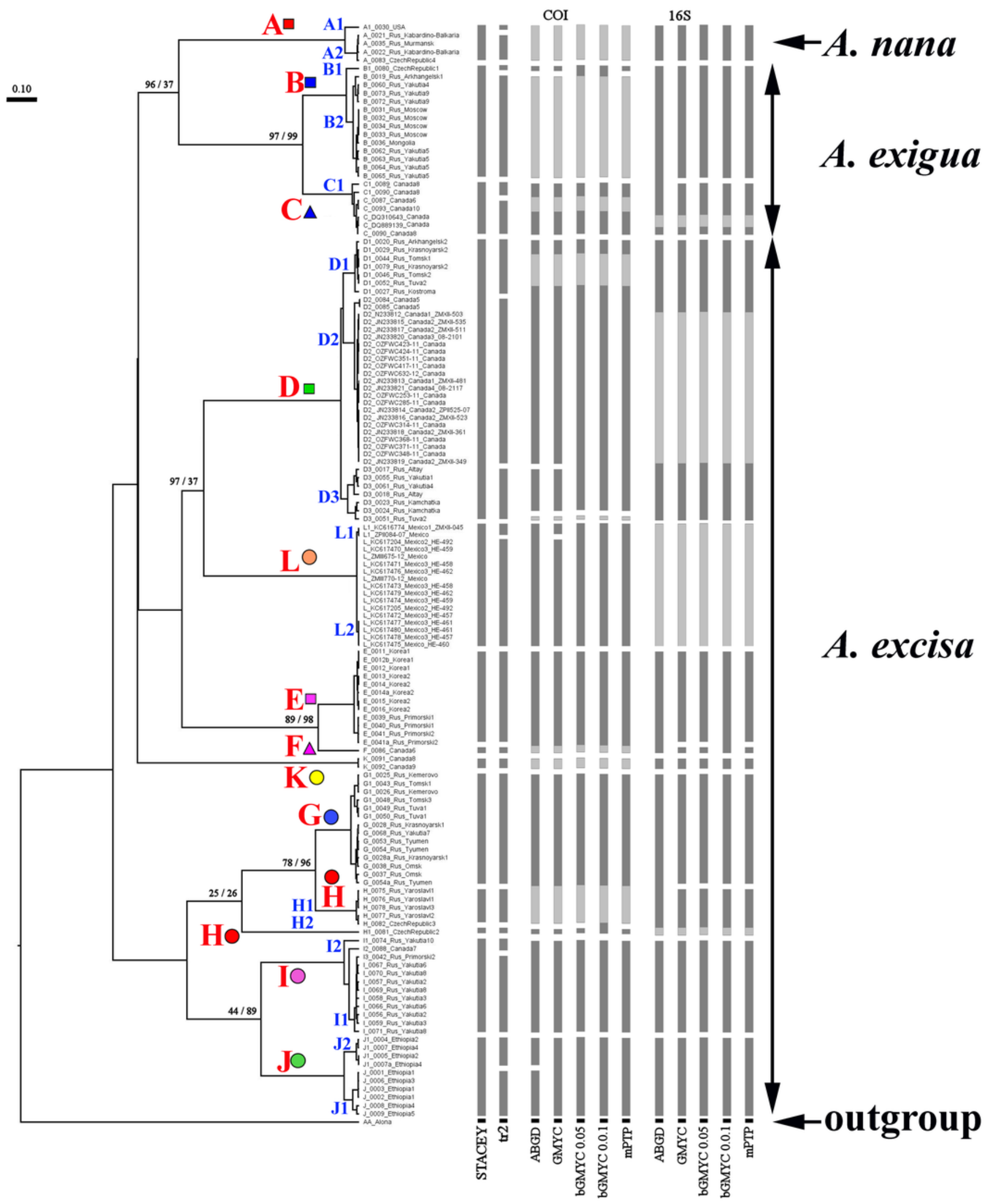


\section{Table $\mathbf{1}$ (on next page)}

Table 1: Genetic diversity of Alonella complexes.

$\mathrm{N}$ - number of sequences; $\mathrm{G}+\mathrm{C}$ - guanine-cytosine content; $\mathrm{n}$ - total number of sites (excluding sites with gaps / missing data); $\mathrm{S}$ - number of segregating (polymorphic) sites; $\mathrm{Hd}$ - haplotype diversity; $\mathrm{h}$ - number of haplotypes; Pi - nucleotide diversity per site; $\mathrm{k}$ - average number of nucleotide differences; Fs - Fu's neutrality statistic (Fu, 1997); R2 - Ramos-Onsins and Rozas R2-statistic (Ramos-Onsins \& Rozas, 2002). 
1

\begin{tabular}{|l|l|l|l|l|l|l|l|l|l|l|}
\hline Groups & $\mathbf{N}$ & $\mathbf{G}+\mathbf{C}$ & $\mathbf{n}$ & $\mathbf{S}$ & $\mathbf{h}$ & $\mathbf{H d}$ & $\mathbf{P i}$ & $\mathbf{k}$ & $\mathbf{F s}$ & $\mathbf{R 2}$ \\
\hline 16S (mitochondrion, rDNA) & & & & & & & & \\
total 16S & 83 & 0.342 & 409 & 184 & 53 & 0.985 & 0.182 & 70.3 & 1.039 & 0.189 \\
excisa complex & 58 & 0.346 & 409 & 155 & 36 & 0.978 & 0.173 & 67.8 & 3.778 & 0.217 \\
exigua complex & 17 & 0.320 & 409 & 52 & 12 & 0.941 & 0.042 & 16.8 & 0.497 & 0.158 \\
nana & 8 & 0.341 & 390 & 125 & 6 & 0.893 & 0.156 & 61.1 & 5.132 & 0.221 \\
COI (mitochondrion, coding) & & & & & & & & \\
total COI & 78 & 0.374 & 626 & 202 & 40 & 0.974 & 0.166 & 83.4 & 5.128 & 0.204 \\
excisa complex & 74 & 0.365 & 474 & 184 & 40 & 0.965 & 0.156 & 74.2 & 7.040 & 0.199 \\
exigua complex & 3 & 0.373 & 626 & 86 & 3 & 1 & 0.037 & 48.8 & 5.279 & 0.357 \\
nana & 2 & 0.377 & 626 & 0 & 1 & - & - & - & - & - \\
\end{tabular}

2 


\section{Table 2 (on next page)}

Table 2: Estimates of evolutionary divergence over sequence pairs between Alonella complexes

We used uncorrected $p$-distance (Nei \& Kumar, 2000). All ambiguous positions were removed for each sequence pair (pairwise deletion option). On this table COI are located above diagonal, 16S - below diagonal. In the line are within groups $p$-distance for $16 \mathrm{~S}$ / COI respectively. 


\begin{tabular}{l|llll}
\hline & outgroup & excisa & exigua & other \\
\hline outgroup & out & 0.219 & 0.209 & 0.216 \\
excisa & 0.216 & $\mathbf{0 . 1 6} / \mathbf{0 . 1 5}$ & 0.202 & 0.203 \\
exigua & 0.236 & 0.197 & $\mathbf{0 . 0 9} / \mathbf{0 . 0 9}$ & 0.048 \\
nana & 0.233 & 0.251 & 0.229 & $\mathbf{0 . 0 1} / \mathbf{0 . 0 1}$ \\
\hline
\end{tabular}

1 